\title{
Two-way in-/congruence in three components of paternalistic leadership and subordinate justice: The mediating role of perceptions of renqing
}

Article

Accepted Version

Ren, H., Zhong, Z., Chen, C. W. and Brewster, C. ORCID: https://orcid.org/0000-0001-5314-1518 (2021) Two-way in-/congruence in three components of paternalistic leadership and subordinate justice: The mediating role of perceptions of renqing. Asian Business \& Management. ISSN 1472-4782 doi: https://doi.org/10.1057/s41291-021-00149-z Available at https://centaur.reading.ac.uk/96633/

It is advisable to refer to the publisher's version if you intend to cite from the work. See Guidance on citing.

To link to this article DOI: http://dx.doi.org/10.1057/s41291-021-00149-z

Publisher: Palgrave Macmillan

All outputs in CentAUR are protected by Intellectual Property Rights law, including copyright law. Copyright and IPR is retained by the creators or other copyright holders. Terms and conditions for use of this material are defined in the End User Agreement. 


\section{www.reading.ac.uk/centaur}

\section{CentAUR}

Central Archive at the University of Reading

Reading's research outputs online 
Two-way in-/congruence in three components of paternalistic leadership and subordinate justice: The mediating role of perceptions of renqing

Abstract This paper examines the effects of two-way congruences and incongruences

Formatted: Font color: Blue authoritarianism, on overall subordinate justice perceptions. We hypothesize that these dyad in-/congruences would differentially predict subordinate overall justice perceptions, with perceptions of renqing as a mediator. With data collected from two-wave surveys in the People's Republic of China, the results indicate that dyad congruences and incongruences between benevolence, morality, and authoritarianism have significant impacts on subordinate perceptions of renqing and, ultimately, their overall justice perception. Our findings underscore that to fully understand the influencing processes of paternalistic leadership on subordinate outcomes, it is important to take into account the context and the different combinations of its three dimensions.

Keywords Paternalistic leadership $\cdot$ Components in-/congruence $\cdot$ Perceptions of renqing $\cdot$ Overall justice $\cdot$ Mediating mechanism 


\section{Introduction}

Paternalistic leadership, which has its cultural roots inThe -Chinese traditional ethics of

Confucianism, includes paternalistic leadership, which involves fatherly benevolence, moral integrity, and strong authority (Chen et al. 2014; Cheng et al. 2004; Farh and Cheng 2000;

Hiller et al. 2019). It combines three dimensions: benevolence, morality, and authoritarianism (Farh and Cheng 2000). Scholars have examined the consequential effects of paternalistic leadership on subordinate and team outcomes in many societies and concluded that paternalistic leadership is more acceptable and prevalent in those regions whose cultures values hierarchy and collectivism (e.g., China, Latin America, Africa, and Middle East) while it is less prevalent in countries characterized as Western, Educated, Industrialized, Rich, and Democratic such as the United States of America (Henrich, Heine and Norenzayan, 2010; Hiller et al. 2019). Indeed, prior studies have gone so far as to highlight the extensive impacts of culture on the effectiveness of paternalistic leadership in different contexts (Hiller et al. 2019). But few have empirically examined how the different combinations of leader's paternalistic behaviors willtrigger subordinates' perceptions of cultural-specific notions (such as renqing in China) and then to-alter their justice perceptions. We ask: How will the two-way combinations of three dimensions of paternalistic leadership affect subordinates' perceptions of renqing and then overall justice?

Most previous work has focused on both the effect of the unitary paternalistic leadership and that of the three components; and found a constantly positive relationship between unitary paternalistic leadership, benevolence and morality effects on subordinate outcomes such as organizational commitment and performance (Chan et al. 2013; Hiller et al. 2019). Recent research (e.g., Cheng et al. 2004; Niu et al. 2009; Tian and Sanchez 2017), however, started to pay attention to the interactive effects of the three components of paternalistic leadership. The evidence indicates that only the two-way interactions (i.e., benevolence $\times$ morality, 
benevolence $\times$ authoritarianism, and morality $\times$ authoritarianism) exert significant effects on subordinate outcomes: The three-way interaction (benevolence $\times$ morality $\times$ authoritarianism) does not significantly relate to them (Cheng et al. 2004). Moreover, previous studies also found that the three two-way interactions tend to exert differential impacts on subordinate outcomes, including identification, compliance, gratitude (Cheng et al. 2004), justice perceptions (Zhou \& Long 2007), work motivation (Niu et al. 2009), and affective trust, knowledge sharing and innovative behavior (Tian and Sanchez 2017).

To further examine the interactive effects, scholars have recommended polynomial regression models with response surface analyses (Edwards, 2002; 2007; Shanock et al., 2010). This approach provides a more nuanced view that traditional moderating analyses cannot offer, in which the relationships between the combination of two predictor variables and outcome variable are detected in a three-dimensional space (Shanock et al., 2010). So far, few studies have touched upon the topic of the two-way congruences and incongruences between the three dimensions of paternalistic leadership and how these combinations impact subordinate outcomes.

One exception is the pioneering work of Wang et al. (2018; p. 686), who proposed "a new typology of paternalistic leadership styles" by identifying three combinations of benevolence and authoritarianism, namely, classical paternalistic leadership (CPL), benevolence-dominant (BDL), and authoritarianism-dominant (ADL); they found both CPL and BDL have a positive relationship with subordinate performance while ADL does not. Wang et al.'s study demonstrated that in-/congruent combinations of benevolence and authoritarianism exist, and differently affect subordinate performance; however, what remains unknown is that how these two-way combinations, especially those involving morality, affect subordinate overall justice perception and whether the Chinese culture-specific construct, renqing, serves as a mediator. 
As with any other aspect of HRM, leadership and justice are concepts that need to be understood in specific contexts (Cooke 2018; Yakob 2020). The regional level (Cooke and Kim 2018) and the national level (Brewster Mayrhofer and Farndale 2018) are particularly important. Social representation theory assumes that every society has its own culturallyspecific representations. Representation is an individual and collective activity of the simultaneous establishment of 'common sense' (Bauer and Gaskell 1999; Moscovici 1981; 1988). To understand any aspect of people management or HRM in China, we have to understand what constitutes 'common sense' in the Chinese context. One specific feature of the Chinese culture is renqing:- There is no direct English-language translation--of renqing.

Renqing has three different meanings: one refers to people's emotional responses triggered by various social situations; the second refers to the resources that an individual can offer to others as gifts and favors; the third means a set of social norms that requires people to express good emotional feelings for others, and to conduct contextually-proper social actions in different situations (Hwang 1987; Wang 2007; Leung et al. 2014). According to Ren, Chen and Chen (2020), in the work context ${ }_{2}$ perceptions of renqing refer to employees' perceptions of the extent to which people's actions in their organizations follow the renqing norm. It involves two dimensions: affective interaction and discretionary consideration. Although renqing is a culturally-specific notion understood and accepted by individuals who are born into such contexts, it does not mean that employees' perceptions of renqing in the workplace are equivalent to or independent of the impacts of contextual factors. It is people's actions, including leader behaviors and coworker interactions, that exert direct effects on the level of renqing perceptions in the workplace. Given that both paternalistic leadership and renqing have cultural roots in the Chinese traditional ethics of Confucianism, they may be significantly related to each other (Farh and Cheng 2000; Hwang 1987; Zhang et al. 2019).

Renqing manifests in every aspect of Chinese social life (Hwang 1987; Jia et al. 2012; 
Yen et al. 2017; Zhang 2006). Many scholars (e.g., Hwang 1987; Leung et al. 2014; Zhang and Yang 1998; 2001) have noted how the renqing norm regulates all interpersonal relationships and guides all social actions in Chinese society. More importantly, Zhang and Yang (1998) found that the renqing norm, as a widespread social representation, also underlies Chinese employees' judgement of distributive justice in the workplace. Then the experience of distributive justice, in conjunction with other justice-relevant information (e.g., procedural justice and interactive justice), will be processed to create the general justice judgment, as has been depicted in the "judgmental phase" by the fairness heuristic theory (Lind, 2001). One typical variable which indicates the general justice judgment is overall justice, which refers to the extent to which employees perceive the justice of their organization as a whole (Ambrose and Schminke 2009; Aryee et al. 2015; Kim and Leung 2007; Kim et al. 2017).

Integrating social representation theory and fairness heuristic theory, we contend that perceptions of renqing, in the workplace, serves as a 'bridge' (a social representation process) that links paternalistic leadership to subordinate views of overall justice. Specifically, when a leader's behaviors show evidence of paternalistic leadership, that will go a long way towards meeting the implicit leadership expectations of Chinese employees, leading to high-levels of perceptions of renqing and, in turn, to significant feelings of overall justice.

We offer the following contributions. First, by integrating social representation theory and fairness heuristic theory, we highlight a consecutive theoretical link from the two-way combinations of benevolence, morality, and authoritarianism, to perceptions of renqing, and to overall justice in the context of Chinese organizations. Our findings of the significant mediating role of perceptions of renqing advance current understandings of the mechanisms underlying the relationships between culture-specific leadership to subordinate outcomes. Second, by using polynomial regression to precisely model the effects of different two-way 
combinations of benevolence, morality, and authoritarianism on subordinate outcomes, we follow the call by Wang et al. (2018) to shed light on the new enhanced typology of paternalistic leadership. Our study highlights the fact that to fully understand the effects of paternalistic leadership on subordinate overall justice one should consider it as a multidimensional rather than a unitary construct (Hiller et al. 2019; Wang et al. 2018; Zhang et al. 2015). In particular, this requires an exploration of the in-/congruent two-way combinations of its three components.

The theoretical framework of this study is shown in Figure 1.

\section{----- Insert Figure 1 about here -----}

\section{Theory and hypotheses}

\section{Paternalistic leadership and the in-/congruent combinations of its components}

In highlighting leadership styles in the Chinese context, Farh and Cheng (2000) developed and defined paternalistic leadership as leaders' behaviors that combines fatherly benevolence, moral integrity and strong authority (Wu et al. 2012, p. 97): benevolence, morality and authoritarianism. Benevolence involves leaders' behavior that demonstrates individualized, holistic care, kindness, and concern for followers' well-being. Morality depicts leaders' pursuit of a moral character, including self-discipline, unselfishness and personal virtues. Authoritarianism refers to absolute authority, control and strict discipline over followers. A quick glance at these definitions of benevolence, morality, and authoritarianism triggers the impression that paternalistic leadership has three paradoxical dimensions, however, the yinyang philosophy, a Chinese traditional ideology, helps to explicate why these three paradoxical dimensions coexist in paternalistic leadership (Chen 2002; Fang 2012; Wu et al. 2012).

The yin-yang philosophy highlights a dynamic, dialectical, and holistic world view 
(Fang 2012), in which paradoxical components such as the three dimensions of paternalistic leadership, actually coexist, interact, and form 'paternalism' as a whole, which affects subordinate outcomes (Cheng et al. 2004). Consequently, scholars (e.g., Hiller et al. 2019) have focused en not only on the effects of the unitary paternalistic leadership but also on those of its three components. Their findings have consistently confirmed the positive effects of the unitary paternalistic leadership, benevolence, and morality, as well as the negative effects of authoritarianism on subordinate outcomes, such as job satisfaction, organizationbased self-esteem and performance (Chan et al. 2013; Hiller et al. 2019). Some scholars examine their interactive effects (Cheng et al. 2004; Niu et al. 2009; Tian and Sanchez 2017) and find that the two-way interactions exert significant effects on subordinate outcomes, but that the three-way interaction does not. In general, such interaction effects support the idea that different combinations of benevolence, morality and authoritarianism affect subordinates differently. However, the traditional analysis of moderation cannot precisely model the impacts of the in-/congruencies that we need to fully understand paternalistic leadership (Wang et al. 2018).

Wang et al. (2018) use polynomial regressions to model the effects of the combinations of two components (benevolence and authoritarianism) of paternalistic leadership on subordinate task performance. Using a Taiwanese military sample, they find that subordinates' task performance is positively related to CPL and BDL, but negatively associated with ADL. These results suggest the need for a closer look at this enhanced typology of paternalistic leadership in order to shed light on the effects of the combinations of its three components.

So, this study offers an enhanced view of paternalistic leadership by bringing its third component - morality - to this new typology. To simplify, we class the BDL and ADL into the incongruence group; and the CPL into the congruence group. Accordingly, we propose and 
define six types in terms of each of the two components of paternalistic leadership ${ }^{1}: \mathrm{B}=\mathrm{M}$ (the congruence of benevolence and morality), $\mathrm{B}=-\mathrm{M}$ (the incongruence of benevolence and morality), $\mathrm{B}=\mathrm{A}$ (the congruence of benevolence and authoritarianism), $\mathrm{B}=-\mathrm{A}$ (the incongruence of benevolence and authoritarianism), $\mathrm{M}=\mathrm{A}$ (the congruence of morality and authoritarianism), $\mathrm{M}=-\mathrm{A}$ (the incongruence of morality and authoritarianism). The congruent combinations: $\mathrm{X}=\mathrm{Y}$ (i.e. $\mathrm{B}=\mathrm{M}, \mathrm{B}=\mathrm{A}$, and $\mathrm{M}=\mathrm{A}$ ) manifest in the continuum from both low to both high, while the incongruent ones: $\mathrm{X}=-\mathrm{Y}$ (i.e. $\mathrm{B}=-\mathrm{M}, \mathrm{B}=-\mathrm{A}$, and $\mathrm{M}=-\mathrm{A}$ ) manifest in the continuum from the combination of low $\mathrm{X}$ and high $\mathrm{Y}$ to that of high $\mathrm{X}$ and low $\mathrm{Y}$.

\section{The in-/congruent combinations of $\mathrm{B}, \mathrm{M}$ and $\mathrm{A}$, and subordinate perceptions of renqing}

To develop our understanding of the two dimensions (affective interaction and discretionary consideration) in perceptions of renqing, we need to clarify meanings. Affective interaction refers to employees' perceptions of the extent to which the renqing norm typically regulates interpersonal interactions within the workplace. The interpersonal interactions of the renqing norm include expressing good emotions (such as respect, trust and sympathy), caring for others and providing help. The other dimension, discretionary consideration, refers to employees' perceptions of the extent to which the renqing norm typically regulates managerial practices within their organizational settings. The renqing norm requires Chinese managers to show flexibility (Zhu et al 2018) by considering specific situations faced by employees and paying attention to both rational criteria (e.g., formal rules) and renqing factors when making personnel decisions.

As we explained before, renqing serve as a 'common sense', underlying the Chinese

\footnotetext{
${ }^{1}$ Note that in this paper ' $\mathrm{X}=\mathrm{Y}$ ' does not mean that ' $\mathrm{X}$ is equal to $\mathrm{Y}$ ' or 'the two values share the same meaning', for $\mathrm{X}$ and $\mathrm{Y}$ are two distinct variables. As in Beus, Lucianetti, \& Arthur (2020) and other studies (e.g., Wang et al., 2018; 2020), we measured the three dimensions of paternalistic leadership using the same response scale, and thus scores from these measures allow us to compare whether leader's behaviors of benevolence and morality (or authoritarianism) are equally frequent or if one is more or less frequent than the other. In particular, ' $\mathrm{X}=\mathrm{Y}$ ' shortly represents that leader's behaviors of benevolence and morality (or authoritarianism) are equally frequent; while ' $\mathrm{X}=-\mathrm{Y}$ ' means that one is more or less frequent than the other.
} 
social representation process; in which leader behaviors are evaluated by the-employees through comparing them with the renqing norm. Although renqing is a culturally-specific notion which is naturally recognized by the individuals who are born in such context, perceptions of renqing highlights how employees perceive people's actions, especially leader behaviors, in line with the renqing norm. Consequently, subordinates' perceptions of renqing vary with the leader's display of benevolence, morality and authoritarianism. Given that both paternalistic leadership and renqing are rooted in the traditional ethics of Confucianism (Farh and Cheng 2000; Wu et al. 2012), which highlights the benevolence most, it is reasonable to expect leader benevolence, which contains leaders' care and concern for subordinate wellbeing (Farh and Cheng 2000), is - to be the component of paternalistic leadership that best meets the renqing norm as conveying good feelings (e.g. care and kindness) for others (Hwang 1987; Leung et al. 2014; Zhang and Yang 2006) and the one that should have a positive effect of benevolence-on subordinates' perceptions of renqing.

The other dimension, morality, refers to leaders' pursuit of moral character. "This moral character ... contains a broad set of Confucian values such as sense of responsibility to subordinates, propriety, tolerance, reasonableness, filial piety, and human-heartedness" (Farh and Cheng 2000, p. 94). Given that leaders' virtues as a moral character are shaped by the social norms in particular regions (Farh and Cheng 2000), we contend that morality also meets the requests of the renqing norm and has positive effects on subordinates' perceptions of renqing. Hence:

Hypothesis 1a Congruence between leader's benevolence and morality $(B=M)$ will be positively related to subordinate perceptions of renqing, that is, subordinate perceptions of renqing will be higher when they perceive benevolence and morality are both high than when both are low. 
Given the most essential requirement of the renqing norm is to express good emotional feelings for others, including showing sympathy, caring for, and helping others (Zhang and Yang 2006), we argue that benevolence will show stronger positive effects on subordinate perceptions of renqing than morality. Therefore, we propose that perceptions of renqing will be higher when subordinates perceive a combined display of high benevolence and low morality than when they perceive an incongruity of low benevolence and high morality:

Hypothesis 1b Incongruence between leader's benevolence and morality $(B=-M)$ will be positively related to subordinate perceptions of renqing, that is, subordinate perceptions of renqing will be higher when they perceive a combination of high benevolence and low morality than that of low benevolence and high morality.

Authoritarianism, which emphasizes control, power and obedience, has been repeatedly confirmed to have negative effects on subordinate outcomes (Hiller et al. 2019). Nonetheless, the interaction/combination of benevolence and authoritarianism has been-proven to be positively associated with subordinate outcomes. Specifically, scholars found that the twoway interaction has positive effects on subordinates' gratitude, compliance, identification (Cheng et al. 2004) and affective trust (Tian and Sanchez 2017). Using polynomial regression, Wang et al (2018) found positive effects of the congruence of benevolence and authoritarianism on subordinate performance. Such results, with the findings that subordinates tend to attribute authoritarianism to good intentions when it is combined with a high-level of benevolence (Chan et al. 2013), suggest it is reasonable to propose that:

Hypothesis 2a Congruence between leader's benevolence and authoritarianism $(B=A)$ will be positively related to subordinate perceptions of renqing, that is, subordinate perceptions of renqing will be higher when benevolence and authoritarianism are both high than when both are low. 
Indeed, authoritarianism has its cultural roots in Chinese patriarchal tradition, wherein the father-son bond is treated as the prototype for leader-subordinate relationships. Chinese society inculcates the obligations of 'followership' into subordinates to legitimate fatherly authority (Farh and Cheng 2000). Nowadays, however, Chinese people, especially younger ones, are becoming more individualistic (concerned with e.g. power, hedonism and selfdirection) and less collective (e.g. tradition and conformity), though not altogether forsaking their Confucian values of societal harmony, virtuous interpersonal behavior, and interpersonal harmony (Ralston et al. 1999). Given that "the power and legitimacy of authority depends on the subordinates' internalization of their roles" (Farh and Cheng 2000, p.103), we propose that employees at the current workplace identify themselves less as traditional 'subordinates' who are required to exhibit conformity to leaders' control and power; and are more likely to assess authoritarianism as a hindrance for interpersonal harmony, leading to low levels of perception of renqing. So:

Hypothesis 2b Incongruence between leader's benevolence and authoritarianism $(\mathrm{B}=-\mathrm{A})$ will be positively related to subordinates' perceptions of renqing, that is, subordinates' perceptions of renqing will be higher when they perceive a combination of high benevolence and low authoritarianism than that of low benevolence and high authoritarianism.

Cheng et al. (2004) indicated the negative effects of the two-way interaction of morality and authoritarianism on subordinates' identification, compliance and gratitude. This, according to the authors, is because in traditional China, when righteous managers carried out policies with an authoritarian approach, they tended to execute severe punishments on the subordinates, no matter what the situation, resulting in people having a cruel and negative impression of them (Pye 1985), leading to a reduction in perceptions of renqing. Hence: 
Hypothesis 3a Congruence between leader's morality and authoritarianism (M=A) will be negatively related to subordinate perceptions of renqing, that is, subordinate perceptions of renqing will be higher when morality and authoritarianism are both low than when both are high.

In contrast, when leaders display high morality combined with low authority, their subordinates tend to form a positive impression of them. Cheng et al.'s (2004) found that the positive correlation between morality and subordinates' responses $\underline{i} \# \underline{\text { sill }}$ be stronger when authoritarianism is low than when it is high. As defined, the incongruence between morality and authoritarianism $(\mathrm{M}=-\mathrm{A})$ manifests in a continuum from the combination of low morality and high authoritarianism to that of high morality and low authoritarianism. Therefore, we hypothesize:

Hypothesis 3b Incongruence between leader's morality and authoritarianism (M=-A) will be positively related to subordinate perceptions of renqing, that is, subordinates' perceptions of renqing will be higher when they perceive a combination of high morality and low authoritarianism than that of low morality and high authoritarianism.

\section{The mediating role of perceptions of renqing}

There have been very few studies of the effects of paternalistic leadership on subordinates' overall justice, although few some studies (e.g., Zhou and Long, 2007) have examined the impacts of the three dimensions of paternalistic leadership on subordinates' views of specific types of organizational justice (e.g., interactional justice). In particular, according to the multilanguage meta-analyses of Hiller et al. (2019), both benevolence and morality exert positive effects on distributive and interactional justice; while authoritarianism only shows a significant negative effects on interactional justice, but is non-significant in relation to other justice perceptions. Moreover, as has been identified by Zhou and Long (2007), the two-way 
interaction of morality and authoritarianism exerts significant negative effects on procedural and distributive justice; and that of benevolence and authoritarianism also has a negative relationship with interactional and informational justice.

Integrating social representation theory and fairness heuristic theory, we contend that perceptions of renqing, in the workplace, are 'common sense' which has been simultaneously established as a social representation process in evaluating leader behaviors and judging justice. In particular, we propose that perceptions of renqing serve as a 'bridge' that links paternalistic leadership to subordinates' views of overall justice. We expect that subordinates' perceptions of renqing vary with the leader's interactive displays of benevolence, morality and authoritarianism, in particular, the two-way in-/congruences of benevolence, morality and authoritarianism. Now we focus on the effects of perceptions of renqing on overall justice.

Many scholars have postulated that Chinese societies employ a different conception of justice (Chiu 1991; Li 1999; Zhang and Yang 2006). This difference has been related to Confucianism's highlighting of ren (benevolence) and $y i$ (righteousness). The former requires people to express affect (qing) to others (Hwang 1987); and the latter requires fulfilling one's moral obligations in any given context (Chiu 1991). The renqing norm, as the most prevalent social norm in Chinese society, is actually a combination of the requirements of Confucian's ren and yi (Hwang 1987). In keeping with this notion, we expect perceptions of renqing, in turn, to directly influence subordinates' views of overall justice.

Additionally, justice-relevant information such as leader behaviors will first influence subordinates' judgment of their own position or status in their team, and then be used to form a judgment of overall justice (Lind 2001; Lind et al. 1998). A critical indicator of position and status in a team can be the quality of interpersonal relationships with others. To some extent, we believe that perceptions of renqing not only underlie Chinese social representation process 
in evaluating leader behaviors and judging justice, but also imply the quality of interpersonal relationships in the workplace, which suggests position and status. These considerations provide the theoretical rationale for proposing that perceptions of renqing serve as a mediator in the relationship between the in-/congruence of leaders' benevolence, morality and authoritarianism and subordinates' overall justice perceptions:

Hypothesis 4 The a) congruence of benevolence and morality (B=M); and b) incongruence of benevolence and morality $(B=-M)$, has a positive indirect effect on subordinates' overall justice perception through their perceptions of renqing.

Hypothesis 5 The a) congruence of benevolence and authoritarianism $(\mathrm{B}=\mathrm{A})$; and $\mathrm{b})$ incongruence of benevolence and authoritarianism $(B=-A)$, has a positive indirect effect on subordinates' overall justice perception through their perceptions of renqing.

Hypothesis 6 The a) congruence of morality and authoritarianism (M=A); and b) incongruence of morality and authoritarianism $(M=-A)$, has a) negative and b) positive indirect effects on subordinates' overall justice perception through their perceptions of renqing.

\section{Method}

\section{Sample and procedures}

We conducted two successive surveys to collect data from seven enterprises located in China. A time-_lagged design was employed to reduce the potential risk of common method bias (Podsakoff et al. 2003). Questionnaires were administered to employees via human resources managers in each enterprise. To assure confidentiality, and to reduce participants' potential concerns about being evaluated, each questionnaire was enclosed within an envelope, and participants were informed that immediately after completing the questionnaire, they should put it back in the envelope, seal it, and then give it to their human resources manager to pass 
In the first wave of surveys, a total of 530 employees reported their perceptions of the leaders' paternalistic leadership and their own demographic information, with a response rate of $88.3 \%$. Two weeks later, questionnaires for measuring employee perceptions of renqing and their overall justice perception were administered to the employees who completed the first survey via the same human resources managers in the same seven enterprises; 464 were returned $(77.3 \%)$, of which 361 responses were matched with the first survey. Excluding the incomplete ones, the final sample pool contained 325 valid paired responses. Of the 325 employees, $66 \%$ were male. Their average age was 33.8 , and the average organizational tenure was 9.6 years. $54.7 \%$ of them had a university degree or above. $44.5 \%$ of the participants occupied managerial positions. $65.5 \%$ worked in state-owned enterprises, with the rest working in private-owned or foreign owned companies.

\section{Measures}

We use six-point Likert-type scales (one: strongly disagree; to six: strongly agree) to avoid the central tendency bias found among Chinese respondents (Yang and Chiu 1987; see Chen et al. 2014, p. 806). We employed translation and back-translation procedures as suggested by Brislin (1986) to translate all English items into Chinese.

Paternalistic leadership. The 15-item version scale developed by Cheng et al. (2014) was used to evaluate subordinates' views of their senior's paternalistic leadership. It has three subscales: benevolence, morality, and authoritarianism; and each consists of five items. Sample items are: "My leader often shows his/ her concern about me" (for benevolence); "My leader takes responsibility on the job and never shirks his/ her duty" (for morality); "My leader appears to be intimidating in front of his/ her subordinates" (for authoritarianism). The CFA results show that the three-factor model fits the data $\left(\chi^{2} / d f=3.565\right.$, RMSEA $=0.089$, 
$\mathrm{NFI}=.923, \mathrm{IFI}=.943, \mathrm{NNFI}=.931, \mathrm{CFI}=.943)$ better than alternative models, indicating good discriminant validity of this three-dimensional scale. The Cronbach's $\alpha$ of three dimensions of paternalistic leadership scale was $.923, .959$, and .797 , respectively.

Perceptions of renqing. The measure of perceptions of renqing was taken from Ren et al. (2020). The scale consists of two dimensions: Affective interaction (9 items) and discretionary consideration (5 items). One sample item of affective interaction is "If an employee or an employee's family is sick, the supervisor and coworkers will visit the patient and express their concerns." One sample item of discretionary consideration is "In managerial practices, my organization will consider the special situations faced by the employees rather than impose uniformity in all cases." The Cronbach's alphas of perceptions of renqing and its two dimensions are $.923, .914$ and .841 , respectively.

Overall justice. The three-item overall justice scale developed by Kim and Leung (2007) was used. One sample item was "Overall, I believe I receive fair treatments from this organization." The Cronbach's $\alpha$ of this scale is .929 .

Control variables. This study included as control variables individual's demographic variables, such as gender, age, organizational tenure, education level and position in the organization, as well as the organization's ownership. We measure the education level by five categories: middle school or below, high school, college, university, and postgraduate; organizational tenure as the number of years worked in the current enterprise; position in the organization as four categories: employees, junior manager, middle manager and senior manager. The organization's ownership was measured using four categories: state-owned, private-owned, foreign-owned and 'others.'

\section{Analysis strategies}

Tests of congruence and incongruence effects. We used polynomial regression and response 
surface analysis (Edwards 2007; Jia et al. 2018) ${ }^{2}$. In testing the hypotheses 1, 2, and 3, we estimated the following equation:

$$
\mathrm{M}=\mathrm{b}_{0}+\mathrm{b}_{1} \mathrm{X}+\mathrm{b}_{2} \mathrm{Y}+\mathrm{b}_{3} \mathrm{X}^{2}+\mathrm{b}_{4} \mathrm{XY}+\mathrm{b}_{5} \mathrm{Y}^{2}+\mathrm{e}
$$

Where $\mathrm{M}$ represents perceptions of renqing; $\mathrm{X}$ and $\mathrm{Y}$ respectively represent two of benevolence, morality and authoritarianism. We then graph the response surfaces in which perceptions of renqing is plotted on the vertical axis, meanwhile $\mathrm{X}$ and $\mathrm{Y}$ are plotted on the perpendicular horizontal axes (Edwards and Parry 1993).

To test the congruence effects of $\mathrm{B}=\mathrm{M}, \mathrm{B}=\mathrm{A}$, and $\mathrm{M}=\mathrm{A}$ (i.e., hypotheses 1a, 2a, and 3a), as specified by Edwards (2007), the key features of the $\mathrm{X}=\mathrm{Y}$ line on the response surface were examined. To claim support for hypotheses of positive (or negative) congruence effect, the slope of this line (i.e., computed as $b_{1}+b_{2}$ ) needs to be positive (or negative) and significantly differ from zero; meanwhile the curvature (i.e., computed as $b_{3}+b_{4}+b_{5}$ ) should be nonsignificant. To test incongruence effect of $B=-M, B=-A$, and $M=-A$ (i.e., hypotheses $1 \mathrm{~b}$, $2 b$, and $3 b$ ), the key features of the $X=-Y$ line on the response surface were examined. To claim support for hypotheses of positive incongruence effect, the slope of this $\mathrm{X}=-\mathrm{Y}$ line (i.e., computed as $b_{1}-b_{2}$ ) should be positive and significantly differ from zero and the curvature (i.e., computed as $b_{3}-b_{4}+b_{5}$ ) needs to be nonsignificant.

Tests of the mediating role of perceptions of renqing. Turning to hypotheses 4, 5, and 6 (i.e., the mediating role of perceptions of renqing in the congruence and incongruence effects

\footnotetext{
2 Polynomial regression models with response surface analyses, as an alternative to difference scores, are advised for commensurate variables that examine in-/congruence between the same variable rated by different subjects (e.g., leaders and followers) or between desired and actual levels of the same variable (e.g., those in person-environment fit studies) (Edwards, $2002 ; 2007)$. The main purpose of this study, however, is not to examine the in-/congruence of two commensurate variables but to use the approach to get nuanced information that traditional moderating analysis cannot offer (Shanock et al., 2010; Wang et al., 2018). Moreover, as in Beus et al. (2020), we measured the three dimensions of paternalistic leadership using the same response scale, and thus scores from these measures allow us to compare whether leader's behaviors of benevolence and morality (or authoritarianism) are equally frequent or if one is more or less frequent than the other. Thus, using commensurate variables is not a major concern.
} 
on subordinates' perceptions of overall justice), we adopted the block variable (Edwards and Cable 2009; Cole et al. 2013). The estimated coefficients in Equation 1 were combined to obtain the block variable. Then perceptions of renqing were regressed on the block variable to obtain the 'a' path regression coefficient. Next, subordinates' views of overall justice were regressed on both perceptions of renqing and the block variable to get the 'b' path (represented by the coefficient for perceptions of renqing on overall justice). Finally, the indirect effect (i.e., $\mathrm{a} \times \mathrm{b}$ ) is calculated and examined by bootstrapping bias-corrected CIs from 10,000 samples (Efron and Tibshirani 1993).

\section{Results}

\section{Confirmatory factor analyses (CFA) and common method variance caution}

A series of CFAs were employed to examine the distinctiveness of five main variables: benevolence, morality, authoritarianism, perceptions of renqing, and views of overall justice (i.e. Model 1). Table 1 shows the results and demonstrates that the baseline five-factor model fits the data well $\left(\chi^{2}=1107.595, \chi^{2} / d f=2.440\right.$, SRMR $=0.054$, RMSEA $=0.067, \mathrm{CFI}=.915$, $\mathrm{IFI}=.915, \mathrm{NNFI}=.907)$. We compared the goodness of baseline five-factor model fit to several alternative models: A four-factor model with the combination of perceptions of renqing and overall justice (Model 2), a three-factor model with the combination of three components of paternalistic leadership (Model 3), and a one-factor model with all five factors combined (Model 4). The findings shown in Table 1 indicate that the fit indices of the fivefactor model are better than all alternative models $\left(\triangle \chi^{2}=502.629,848.256,2547.914\right.$, respectively, $\mathrm{p}<.01$ ), suggesting reliable distinctiveness of these variables. As recommended by Podsakoff et al. (2003), we use the marker variable method to detect any common method variance (CMV) in our study. In particular, we constructed a latent variable called "CMV" by loading all indicators of the five theoretical variables based on the baseline model, and the 
six-factor model $\left(\chi^{2}=921.756, \chi^{2} / d f=2.184\right.$, SRMR $=0.042$, RMSEA $=0.060$, CFI $=.935$, $\mathrm{IFI}=.935, \mathrm{NNFI}=.923)$ fits the data better than the baseline five-factor model, but the improvement of the goodness of fit was slight $\left(\triangle \chi^{2}=179.839, \triangle \mathrm{df}=32, \mathrm{p}<0.05\right)$.

Additionally, we calculated the average variance extracted (AVE) by the "CMV", and it is 0.43 , which was below the cutoff $(0.50)$ to identify the presence of a latent construct (Dulac et al., 2008; Hair et al., 2009). In conclusion, though CMV may exist, we believe it does not undermine the research validity of the present study.

----- Insert Table 1 and Table 2 about here -----

\section{Hypotheses testing}

In Table 2, we present the means, standard deviations, correlations and alphas among all variables. We find that both benevolence and morality are positively associated to-with subordinates' perceptions of renqing ( $r=.557$ and .568 , respectively, $\mathrm{p}<0.01)$ and their views of overall justice $(r=.433$ and .492 , respectively, $\mathrm{p}<0.01)$ while authoritarianism is not $(r=-.118, \mathrm{p}<0.05$, and $r=-.082$, n.s., respectively). Consistent with the findings of prior studies (Cheng et al. 2004; Farh and Cheng 2000; Hiller et al. 2019), leader authoritarianism is negatively related to benevolence and morality $(r=-.160$ and -.214 , respectively, $\mathrm{p}<0.01)$. We then conducted polynomial regression and bootstrapping to test our hypotheses.

Hypotheses 1a and $1 \mathrm{~b}$ predicted positive effects of in-/congruence of benevolence and morality on subordinate perceptions of renqing. As shown in Table 3, we find a significant $\Delta R^{2}$ between the two models $(0.298, p<.01)$, indicating that benevolence and morality significantly affect perceptions of renqing after controlling for the demographic variables and ownership dummies. Thus, it is appropriate to conduct the response surface (Cole et al. 2013) as shown in Fig. 2a. We estimated the slopes and curvatures along the $B=M$ and $B=-M$ lines for the congruent and incongruent effects of benevolence and morality on perceptions of 
renqing. As seen in Table 3, we find a significant positive slope of $0.318(\mathrm{p}<0.01)$ and a positive curvature of 0.053 (n.s.) for the $B=M$ line; these suggest the positive effect of $B=M$ on perceptions of renqing. We graph this relationship in Fig. 2b. As shown, perceptions of renqing improved as the levels of $\mathrm{B}=\mathrm{M}$ increased, suggesting support for $\mathrm{H} 1 \mathrm{a}$. Also as shown in Table3, we obtain a negative slope (-0.183, n.s.) and a negative curvature $(-0.092$, n.s.) for the $B=-M$ line; these indicate a negative but not significant relationship between $B=-M$ and perceptions of renqing. Fig. $2 \mathrm{c}$ shows the relationship between $\mathrm{B}=-\mathrm{M}$ and perceptions of renqing. H1b is not supported.

----- Insert Table 3 and Figure 2a, 2b, and 2c about here -----

Turning to Hypotheses $2 \mathrm{a}$ and $2 \mathrm{~b}$, which examine the congruence and incongruence effects of benevolence and authoritarianism on subordinate perceptions of renqing, we report the results (M1 and M3) in Table 3. Similarly, we obtain a significant $\Delta R^{2}$ between the two models $(0.212, p<.01)$ and graph the response surface as shown in Fig. 3a. The slopes and curvatures along the $\mathrm{B}=\mathrm{A}$ and $\mathrm{B}=-\mathrm{A}$ lines were estimated. Table 3 shows we obtain a significant positive slope $(0.300, \mathrm{p}<0.01)$ and a positive curvature of 0.085 (n.s.) for the $\mathrm{B}=\mathrm{A}$ line and also a positive slope $(0.334, \mathrm{p}<0.01)$ and a positive curvature $(0.025$, n.s. $)$ for the $B=$ $-\mathrm{A}$ line. These indicate positive relationships between $\mathrm{B}=\mathrm{A}$ and perceptions of renqing and between $\mathrm{B}=-\mathrm{A}$ and perceptions of renqing. We plot these two relationships in Fig. $3 \mathrm{~b}$ and $3 \mathrm{c}$. As shown, both the two relationships are significantly positive, supporting $\mathrm{H} 2 \mathrm{a}$ and $\mathrm{H} 2 \mathrm{~b}$.

----- Insert Figure 3a, 3b, and 3c about here -----

Similarly, we tested the effects of the in-/congruence of morality and authoritarianism on subordinate perceptions of renqing, posited in H3a and H3b. As shown in Table 3 (M1 and M4), we obtain a significant $\Delta R^{2}$ between the two steps $(0.256, p<.01)$ and graph the response surface in Fig. $4 \mathrm{a}$. We estimate the slopes and curvatures along the $\mathrm{M}=\mathrm{A}$ and $\mathrm{M}=-\mathrm{A}$ 
lines. The results indicate a significant positive slope $(0.302, \mathrm{p}<0.01)$ and a positive curvature of 0.105 (n.s.) for the $\mathrm{M}=\mathrm{A}$ line, so $\mathrm{H} 3 \mathrm{a}$ iwas not supported. We also obtain a positive slope $(0.350, \mathrm{p}<0.01)$ and a positive curvature $(0.073$, n.s. $)$ for the $\mathrm{M}=-\mathrm{A}$ line. These indicate a positive relationship between $\mathrm{M}=-\mathrm{A}$ and perceptions of renqing, supporting H3b. We plot these two relationships in Fig. 4b and 4c. As shown, both are significantly positive, so $\mathrm{H} 3 \mathrm{~b}$ is supported but $\mathrm{H} 3 \mathrm{a}$ is not.

----- Insert Figure 4a, 4b, and 4c about here -----

Hypotheses 4, 5 and 6 suggested the congruence (a) and incongruence (b) effect of three components of paternalistic leadership on subordinates' views of overall justice is mediated by perceptions of renqing. As shown in Table 4 , the block variable for $B=M$ and $B=-M$ is positively related to perceptions of renqing (path $\mathrm{a}=0.548$ and -0.500 , respectively, $\mathrm{p}<0.01$ ). Additionally, perceptions of renqing are positively related to overall justice (path $b=0.293$ and 0.354 , respectively, $\mathrm{p}<0.01$ ), and the block variable is significantly associated with overall justice for $\mathrm{B}=\mathrm{M}$ (path $\mathrm{c}^{\prime}=0.323, \mathrm{p}<0.01$ ) and for $\mathrm{B}=-\mathrm{M}$ (path $\mathrm{c}^{\prime}=-.231, \mathrm{p}<0.01$ ) when perceptions of renqing entered the regression model. Finally, bias-corrected CIs with 10000 bootstrapped samples of the indirect effect $(a b)$ of $B=M(a b=0.243,99 \%$ CI $[0.086$, $0.450])$ and that of $\mathrm{B}=-\mathrm{M}(\mathrm{ab}=-.350,99 \% \mathrm{CI}[-0.611,-0.153])$ on views of overall justice exclude zero, thereby providing support for $\mathrm{H} 4 \mathrm{a}$ and $\mathrm{H} 4 \mathrm{~b}$.

Similarly, as shown in Table 4, we obtain significant positive coefficients of path a ( 0.528 and 0.542 , respectively, $\mathrm{p}<0.01)$ between the block variable and perceptions of renqing for $\mathrm{B}=\mathrm{A}$ and $\mathrm{B}=-\mathrm{A}$. We also obtain significant positive coefficients of path $\mathrm{b}(0.344$ and 0.311 , respectively, $\mathrm{p}<0.01$ ) between perceptions of renqing and overall justice after the block variables of $\mathrm{B}=\mathrm{A}$ and $\mathrm{B}=-\mathrm{A}$ were controlled for. Moreover, the effect of the block variables of $\mathrm{B}=\mathrm{A}$ and $\mathrm{B}=-\mathrm{A}$ on overall justice (path $\mathrm{c}^{\prime}$ ) are 0.272 and 0.325 (both $\mathrm{p}<0.01$ ) 
respectively when perceptions of renqing entered. Finally, bias-corrected CIs with 10000 bootstrapped samples of the indirect effect $(a b)$ of $B=A(a b=0.279,99 \%$ CI $[0.122,0.486])$ and that of $\mathrm{B}=-\mathrm{A}(\mathrm{ab}=0.309,99 \% \mathrm{CI}[0.122,0.565])$ on views of overall justice exclude zero, thereby providing support for H5a and H5b.

Turning to Hypotheses $6 \mathrm{a}$ and $6 \mathrm{~b}$, as seen in Table 4, the results indicate that the block variables of $\mathrm{M}=\mathrm{A}$ and $\mathrm{M}=-\mathrm{A}$ are positively related to perceptions of renqing (path $\mathrm{a}=0.511$ and 0.536 , respectively, $\mathrm{p}<0.01)$. Furthermore, perceptions of renqing are positively associated with views of overall justice (path $\mathrm{b}=0.367$ and $0.338, \mathrm{p}<0.01$ ) when the block variables of $\mathrm{M}=\mathrm{A}$ and $\mathrm{M}=-\mathrm{A}$ are controlled for. As for path c', the coefficients between the block variables of $\mathrm{M}=\mathrm{A}$ and $\mathrm{M}=-\mathrm{A}$ and overall justice became 0.239 and 0.284 (both $\mathrm{p}<$ 0.01) respectively when perceptions of renqing are considered. Finally, bias-corrected CIs with 10000 bootstrapped samples of the indirect effect $(a b)$ of $M=A(a b=0.272,99 \% \mathrm{CI}$ $[0.124,0.466])$ and that of $\mathrm{M}=-\mathrm{A}(\mathrm{ab}=0.280,99 \% \mathrm{CI}[0.115,0.496])$ on views of overall justice exclude zero, thereby providing support for H6a and H6b.

\section{----- Insert Table 4 about here -----}

\section{Discussion}

Our paper explores the influencing process through which the dyad congruence and incongruence of three components of paternalistic leadership (i.e., benevolence, morality and authoritarianism) affect Chinese subordinates' views of overall justice (via the transmission of perceptions of renqing). The results supported the prediction that these in-/congruencies significantly affect subordinate perceptions of renqing such that $\mathrm{B}=\mathrm{M}$ and $\mathrm{B}=\mathrm{A}$ positively relate to perceptions of renqing, and so does $\mathrm{B}=-\mathrm{A}$ and $\mathrm{M}=-\mathrm{A}$. Against our expectations, $\mathrm{B}=-\mathrm{M}$ is negatively, albeit non-significantly, associated with perceptions of renqing ( $\mathrm{H} 1 \mathrm{~b})$ 
and the congruence of $\mathrm{B}=\mathrm{M}$ is significantly positively related to perceptions of renqing $(\mathrm{H} 3 \mathrm{a})$. More importantly, our study reveals a mediating mechanism such that the effects of the congruence and incongruence of the three components of paternalistic leadership on subordinates' views of overall justice are significantly transmitted by perceptions of renqing, mainly in terms of the partial mediation patterns. The bootstrapping results indicate that perceptions of renqing exert significant indirect effects in the relationships between each dyad in-/congruence of benevolence, morality, authoritarianism and subordinates' views of overall justice.

A plausible explanation regarding the non-significant negative effect of $B=-M$ on perceptions of renqing may be that morality and benevolence are not equally strong: Morality has a stronger effect on perceptions of renqing than benevolence has. As seen in Table 3 (M2), the relationship between morality and perceptions of renqing was significantly positive $(0.367, \mathrm{p}<0.01)$ while that between benevolence and perceptions of renqing was positive but nonsignificant $(0.097$, n.s.). These findings indicate that subordinates who perceive highlevels of benevolence are likely to perceive higher renqing only when they perceive their leader as having high morality. Our finding of the positive effects of $\mathrm{M}=\mathrm{A}$ on perceptions of renqing are inconsistent with some previous research (e.g., Cheng et al. 2004).

In sum, our study suggests that leaders cannot improve subordinate perceptions of renqing and ultimately their views of overall justice by simply showing their individualized, holistic care, kindness, and concern towards the subordinates unless subordinates also perceive their leaders' pursuit of personal virtues and moral character. They can achieve this goal by employing both high levels of morality and authoritarianism.

\section{Theoretical implications}

Our findings contribute to current understandings of paternalistic leadership in the 
Chinese context in three ways. First, by integrating social representation theory and fairness heuristic theory, we proposed and confirmed a consecutive theoretical link from the two-way combinations of benevolence, morality, and authoritarianism, to perceptions of renqing, and to of overall justice in the context of Chinese organizations. Interestingly, our findings indicate that when a leader conducts benevolence without morality, subordinates do not perceive much renqing and overall justice. In other words, it seems that leaders need to conform to paternalistic leadership, as identified by Cheng et al. (2004). Someone who is caring, magnanimous (i.e., benevolent) should in addition be setting a moral example, in order to improve subordinates' perceptions of renqing, and in turn their overall justice.

Additionally, inconsistent with prior findings (e.g., Cheng et al., 2004), our results suggest that when a leader behaves morally as well as authoritatively subordinates might not form an inhumane and cruel impression of that leader but instead may perceive high-levels of renqing and overall justice. More importantly, our findings of the significant mediating role of perceptions of renqing, a Chinese-specific culture-related construct, advance current understandings of the mechanism underlying the relationships between culture-specific leadership and subordinate outcomes.

Second, by using the polynomial regression to precisely model the effects of the different combinations of benevolence, morality and authoritarianism on subordinate outcomes, we followed the call by Wang et al. (2018) to shed light on a new enhanced typology of paternalistic leadership. Our study highlights that to fully understand the effects of paternalistic leadership it should be considered as a multidimensional, rather than unitary, construct (Hiller et al., 2019; Wang et al., 2018; Zhang et al., 2015). Accordingly, we recommend that scholars not only explore the interactive effects of the three components, but also examine their in-/congruent combinations. Our study illustrates that in-/congruent combinations of the three components of paternalistic leadership significantly but 
differentially affect subordinates' perceptions of renqing and ultimately their views of overall justice. In particular, all three congruences (i.e., $\mathrm{B}=\mathrm{M}, \mathrm{B}=\mathrm{A}$, and $\mathrm{M}=\mathrm{A}$ ) and two incongruences (i.e., $\mathrm{B}=-\mathrm{A}$ and $\mathrm{M}=-\mathrm{A}$ ) exert significant positive effects on perceptions of renqing; while $\mathrm{B}=-\mathrm{M}$ shows negative, albeit nonsignificant, impacts. Moreover, our study also advances the current understanding of the mixed findings regarding authoritarianism effects (negative or null effects) in previous studies (e.g. Chan et al. 2013; Tian \& Sanchez 2017) by highlighting its congruence and incongruence with the two other components of paternalistic leadership.

\section{Practical implications}

Paternalistic leadership prevails in many societies that have cultural contexts that value collectivism and hierarchy (Farh and Cheng 2000; Hiller et al. 2009). Our theory on the influencing processes of the in-/congruent effects of paternalistic leadership's three components, subordinate perceptions of renqing and overall justice, has significant implications for Chinese managers and possibly those in other collectivist countries in East Asia, Middle East, Africa, and Latin America. Outside the Chinese context subordinate perceptions of renqing may not have such an impact but we speculate that, nonetheless managers in paternalistic contexts should enact the combinations of the three dimensions of paternalistic leadership, i.e. benevolence, morality and authoritarianism, to enhance subordinate perceptions of overall justice. Meanwhile, organizations should design their leadership training programs accordingly.

Specifically, leaders who need to conform to paternalistic leadership should in addition be setting a moral example in order to improve subordinates' views of overall justice.

Moreover, leaders should implement those managerial practices which help to trigger social interactions and decision-making in accordance with the Chinese social representation of 
adhering to the renqing norm.

\section{Limitations and future directions}

It is essential to consider our findings in light of the following limitations. First, our study is dependent on context (Cooke 2018); in a non-Chinese society the construct of renqing will not exist and any equivalent will almost certainly include a different set of cultural assumptions. We encourage similar research in other contexts to test the generalisability of our conclusions.

Second, despite this study's use of two-wave surveys in collecting data, its correlational design does not permit conclusive statements about causality from the relationships between and among key variables. Therefore, we suggest researchers employ experimental or qualitative methods to shed light on the causal effects.

Third, employees were the only data source for the variables in this study and the mediator (perceptions of renqing) and the dependent variable (views of overall justice) were assessed at the same time. We acknowledge the possibility that CMV may have biased some of our results. Thus, we recommend that future studies employ multiple data sources with a three-time lagged design to collect antecedents, mediators and outcomes at separate times.

Our data suggest that the congruent and incongruent combinations of paternalistic leadership elements differentially affect subordinate perceptions of renqing and, ultimately, overall justice. It therefore highlights the significance, at least in Chinese communities, of perceptions of renqing as a potential transmission mechanism in the relationships between other external antecedents (such as paradoxical leadership) and subordinate outcomes.

Besides, the examinations of other moderating and/ or mediating mechanisms drawing on the theories of implicit leadership (Den et al. 1999; Epitropaki and Martin 2004), or social categorization (Turner and Reynolds 2010) might prove helpful. Moreover, since the potential 
impact of the in-/congruent combinations effects of benevolence, morality and authoritarianism on employees' outcomes may also vary over time, we recommend future research examines them longitudinally.

\section{Conclusion}

We contribute to the literature on paternalistic leadership, workplace renqing and overall justice. We have advanced current understandings of the linking mechanism between the in/congruent combinations of three components of paternalistic leadership and subordinates' overall justice by bringing in the mediating role of perceptions of renqing (see the calls for such research: Wang et al. 2018; Wu et al., 2012). Our findings demonstrate the significant but differential effects of the congruences (i.e., $\mathrm{B}=\mathrm{M}, \mathrm{B}=\mathrm{A}$, and $\mathrm{M}=\mathrm{A}$ ) and incongruences (i.e., $\mathrm{B}=-\mathrm{M}, \mathrm{B}=-\mathrm{A}$, and $\mathrm{M}=-\mathrm{A}$ ) on subordinate perceptions of renqing. In detail, all three congruencies and two incongruences $(\mathrm{B}=-\mathrm{A}$ and $\mathrm{M}=-\mathrm{A})$ exert positive effects while $\mathrm{B}=-$ M shows negative impact. The relationships between each in-/congruence and subordinates' overall justice perceptions are significantly transmitted by perceptions of renqing. We take a step to explore the influencing mechanism of paternalistic leadership, especially that of dyad congruences and incongruences of its three components. Future studies need to be conducted in other cultural contexts to obtain a fuller understanding of the moderators and mediators in the link between paternalistic leadership and subordinates' outcomes.

\section{References}

Ambrose, M. L., \& Schminke, M. (2009). The role of overall justice judgments in organizational justice research: A test of mediation. Journal of Applied Psychology, 94(2), 491-500.

Aryee, S., Walumbwa, F. O., Mondejar, R., \& Chu, C. W. L. (2015). Accounting for the influence of overall justice on job performance: Integrating self-determination and social exchange theories. Journal of Management Studies, 52(2), 231-252. 
Bauer, M. W., \& Gaskell, G. (1999). Towards a paradigm for research on social representations. Journal for the theory of social behavior, 29(2), 163-186.

Beus, J. M., Lucianetti, L., \& Arthur, W. (2020). Clash of the climates: examining the paradoxical effects of climates for promotion and prevention. Personnel Psychology, 73: 241-269.

Brewster, C., Mayrhofer, W., \& Farndale, E. (Eds.). (2018). Handbook of Research on Comparative Human Resource Management. (2 ed.). Cheltenham: Edward Elgar.

Brislin, R. W. The wording and translation of research instruments. In W Lonner and J Berry (Eds.) Field methods in cross-cultural research 137-164. Beverly Hills, CA: Sage. 1986.

Chan, S. C., Huang, X., Snape, E., \& Lam, C. K. (2013). The Janus face of paternalistic leaders: Authoritarianism, benevolence, subordinates' organization-based self-esteem, and performance. Journal of Organizational Behavior, 34, 108-128.

Chen, M. J. (2002). Transcending paradox: The Chinese 'middle way' perspective. Asian Pacific Journal of Management, 19(2/3): 179-199.

Chen, X.-P., Eberly, M. B., Chiang, T. J., Farh, J. L., \& Cheng, B. S. (2014). Affective trust in Chinese leaders linking paternalistic leadership to employee performance. Journal of Management, 40, 796-819.

Chen Y., Friedman R., Yu E., Fang W., \& Lu X. (2009). Supervisor-subordinate guanxi: Developing a three-dimensional model and scale. Management and Organization Review 5(3), 375-399.

Cheng, B. S., Chou, L. F., Wu, T. Y., Huang, M. P., \& Farh, J. L. (2004). Paternalistic leadership and subordinate responses: Establishing a leadership model in Chinese organizations. Asian Journal of Social Psychology, 7(1): 89-117.

Cheng, B. S., Boer, D., Chou, L. F., Huang, M. P. et al. (2014). Paternalistic leadership in four East Asian societies: Generalizability and cultural differences of the triad model. Journal of Cross-Cultural Psychology, 45(1) 82-90. 
Chiu, C. (1991). Righteousness: The notion of justice in Chinese societies. In C. F. Yang \& H. S. R. Kao (Eds.), Chinese People and Chinese Mind: The Cultural Tradition. Taipei, Taiwan: Yuan-Liu Publishing Co (in Chinese).

Cole, M. S., Carter, M. Z., \& Zhang, Z. (2013). Leader-team congruence in power distance values and team effectiveness: the mediating role of procedural justice climate. Journal of Applied Psychology, 98(6), 962-973.

Cooke, F. L. (2018). Concepts, contexts, and mindsets: Putting human resource management research in perspective. Human Resource Management Journal, 28(1): 1-13.

Cooke, F. 1., \& Kim, S. (2018). Routledge Handbook of Human Resource Management in Asia. Abigndon: Routledge.

Den Hartog, D. N., House, R. J., Hanges, P. J., Ruizquintanilla, S. A., Dorfman, P. W., \& Abdalla, I. A., et al. (1999). Culture specific and cross-culturally generalizable implicit leadership theories: are attributes of charismatic/transformational leadership universally endorsed?. Leadership Quarterly, 10(2), 219-256.

Dulac, T., Coyle-Shapiro, J. A., Henderson, D. J., \& Wayne, S. J. 2008. Not all responses to breach are the same: The interconnection of social exchange and psychological contract processes in organizations. Academy of Management Journal, 51(6), 1079 - 1098.

Edwards, J. R. (2007, April). The accumulation of knowledge in person-environment fit research. Paper presented at the annual meeting of the Society for Industrial and Organizational Psychology, New York.

Edwards, J. R., \& Cable, D. A. (2009). The value of value congruence. Journal of Applied Psychology, 94, 654-677

Edwards, J. R., \& Parry, M. E. (1993). On the use of polynomial regression equations as an alternative to difference scores in organizational research. The Academy of Management Journal, 36(6), 1577-1613.

Efron, B., \& Tibshirani, R. J. (1993). An introduction to the bootstrap. Boca Raton, FL: Chapman \& Hall/CRC. 
Epitropaki, O., \& Martin, R. (2004). Implicit leadership theories in applied settings: Factor structure, generalizability, and stability over time. Journal Applied Psychology, 89(2), 293 310.

Farh, J. L., \& Cheng, B. S. (2000). A Cultural analysis of paternalistic leadership in Chinese organizations. In: J. T. Li, Tsui, A. S. \& E. Weldon (Eds). Management and Organizations in the Chinese Context, pp. 94-127. London: Macmillan.

Farh J., Earley P., \& Lin S. (1997). Impetus for action: A cultural analysis of justice and extrarole behavior in Chinese Society. Administration Science Quarterly 42(3), 421-444.

Fang, T. (2012). Yin Yang: A new perspective on culture. Management and Organization Review, 8(1): 25-50.

Hair, J. F., Black, W. C., Babin, B. J., \& Anderson, R. E. 2009. Multivariate Data Analysis (7th ed). Upper Saddle River: Prentice Hall.

Henrich, J., Heine, S. J., \& Norenzayan, A. (2010). The weirdest people in the world? Behavioral and Brain Sciences, 33, 1-75.

Hiller, N. J., Sin, H. P., Ponnapalli, A. R., \& Ozgen, S. (2019). Benevolence and authority as WEIRDly unfamiliar: A multi-language meta-analysis of paternalistic leadership behaviors from 152 studies. The Leadership Quarterly, 30, 165-184.

Hwang, K. K. (1987). Face and favor: The Chinese power game. American Journal of Sociology, 92, 944-974.

Jia, J. F., Yan, J. Q, Cai, Y. H., \& Liu, Y. P. (2018). Paradoxical leadership incongruence and Chinese individuals' followership behaviors: moderation effects of hierarchical culture and perceived strength of human resource management system. Asian Business \& Management, 17, 313-338.

Jia, L., You, S., \& Du, Y. (2012). Chinese context and theoretical contributions to management and organization research: A three-decade review. Management and Organization Review, 8(1), 173-209.Kim, S. L., Kim, M., \& Yun, S. (2017). What do we need for creativity? The interaction of perfectionism and overall justice on creativity. Personnel Review, 46(1), 
$154-167$.

Kim, T. Y., \& Leung, K. (2007). Forming and reacting to overall fairness: A cross-cultural comparison. Organizational Behavior and Human Decision Processes, 104(1), 83-95.

Leung, K., Chen, Z., Zhou, F., \& Kai L. (2014). The role of relational orientation as measured by face and renqing, in innovative behavior in China: An indigenous analysis. Asia Pacific Journal of Management, 31(1), 105-126.

Li, M. C. (1993). The cultural difference of in-group favoritism: A comparison between Chinese and American undergraduates. In K. S. Yang \& A. B. Yue (Eds.), The Psychology and Behavior of the Chinese (1992). Taipei, Taiwan: Kuei-Kuan Publishing Co (in Chinese).

Lind, E. A. (2001). Fairness heuristic theory: justice judgments as pivotal cognitions in organizational relations. In J. Greenberg \& R. Cropanzano (Eds.), Advances in overall fairness (pp. 56-88). Stanford, CA: Stanford University Press.

Lind, E. A., Kray, L., \& Thompson, L. (1998). Primary effects in justice judgments: Testing predictions from fairness heuristic theory. Organizational Behavior \& Human Decision Processes, 85(2), 189-210.

Moscovici S. (1981). On social representations. In J. Forgas (Ed.), Social Cognition: Perspectives on Everyday Understanding (pp. 181-209). London, England: Academic Press.

Moscovici S. (1988). Notes towards a description of social representations. European Journal of Social Psychology, 18(3), 211-250.

Niu, C. P., Wang, A. C., \& Cheng B. S. (2009). Effectiveness of a moral and benevolent leader: Probing the interactions of the dimensions of paternalistic leadership. Asian Journal of Social Psychology, 12, 32-39.

Podsakoff, P. M., Mackenzie, S. B., Lee, J. Y., \& Podsakoff, N. P. (2003). Common method biases in behavioral research: a critical review of the literature and recommended remedies. Journal of Applied Psychology, 88(5), 879-903. 
Pye, L.W. (1985). Asia Power and Politics. Cambridge, MA: Harvard University Press.

Ralston, D. A., Egri, C. P., Stewart, S., Terpstra, R. H., \& Yu K. (1999). Doing business in the 21st century with the new generation of Chinese managers: A study of generational shifts in work values in china. Journal of International Business Studies, 30(2), 415-427.

Ren, H., Chen, C. W. Z., and Chen, Y. L. (2020). Between culture and satisfaction: Mediating roles of perceptions of renqing and rules. Asia Pacific Journal of Human Resources. doi:10.1111/ 1744-7941.12256

Shi, G., Shi, Y., Chan, A. K. K., Liu, M. T., \& Fam K. S. (2011). The role of renqing in mediating customer relationship investment and relationship commitment in China. Industrial Marketing Management, 40(4), 496-502.

Tian, Q., \& Sanchez, J. I. (2017). Does paternalistic leadership promote innovative behavior? The interaction between authoritarianism and benevolence. Journal of Applied Social Psychology, 47(5), 235-246.

Turner, J. C., \& Reynolds, K. J. (2010). The story of social identity. In T. Postmes, \& N. Bramscpmbe (Eds.), Rediscovering Social Identity: Core Sources (pp. 13-32). Hove: Psychology Press.

Wang, A. C., Tsai, C. Y., Dionne, S. D., Yammarino, F. J., Spain, S. M., Ling, H. C., \& Cheng, B. S. (2018). Benevolence-dominant, authoritarianism-dominant, and classical paternalistic leadership: Testing their relationships with subordinate performance. The Leadership Quarterly, 29(6), 686-697.

Wang, A. C., Chen, Y., Hsu, M. S., Lin, Y. C., \& Tsai, C. Y. (2020). Role-based paternalistic exchange: explaining the joint effect of leader authoritarianism and benevolence on culture-specific follower outcomes. Asia Pacific Journal of Management, 1-23.

Wang, C. L. (2007). Guanxi vs. relationship marketing: Exploring underlying differences. Industrial Marketing Management, 36(1), 81-86.

Wu, M., Huang, X., Li, C., \& Liu, W. (2012). Perceived interactional justice and trust-insupervisor as mediators for paternalistic leadership. Management and Organization 
Review, 8(1), 97-121.

Yakob, R. (2020). Context, competencies, and local managerial capacity development: a longitudinal study of HRM implementation at Volvo Car China. Asian Business \& Management, 19, 582-609.

Yen, D. A., Abosag, I., Huang, Y. A., \& Nguyen, B. (2017). Guanxi, GRX (ganqing, renqing, xinren) and conflict management in sino-US business relationships. Industrial Marketing Management, 66, 103-114.

Zhang, H., Han, R., Wang, L. et al. (2019). Social capital in China: a systematic literature review. Asian Business \& Management. doi:10.1057/s41291-019-00081-3.

Zhang, Y., Huai, M., \& Xie, Y. (2015). Paternalistic leadership and employee voice in China: A dual process model. The Leadership Quarterly, 26, 25-36.

Zhang, Z. X. (2006). Chinese conceptions of justice and reward allocation. In U. Kim, K. S. Yang, \& K. K. Hwang (Eds.) Indigenous and cultural psychology: Understanding people in context (p. 403-420). New York: Springer.

Zhang, Z. X., \& Yang, C. F. (1998). Beyond distributive justice: the reasonableness norm in Chinese reward allocation. Asian Journal of Social Psychology 1(3), 253-269.

Zhang, Z. X., \& Yang, C. F. (2001). An investigation of the concept of renqing. In C. F. Yang (Ed.) Interpersonal relationship, trust, and affect (p. 223-246). Taipei: Yuan Liu (in Chinese).

Zhou, H., \& Long L. R. (2007). Relationship between paternalistic leadership and organizational justice. Acta Psychologica Sinica 39(5), 909-917 (in Chinese).

Zhu, J., Xu, S., Ouyang, K. et al. (2018). Ethical leadership and employee pro-social rulebreaking behavior in China. Asian Business \& Management, 17, 59-81. 
Table 1 Comparison of alternative measurement models

\begin{tabular}{|c|c|c|c|c|c|c|c|c|c|}
\hline Models & Factors & $\cdot \cdot \cdot d f)$ & $\cdot \cdot d f$ & $\triangle \cdot$ & SRMR & RMSEA & CFI & IFI & NNFI \\
\hline 1 & Five factors: $\mathrm{B}, \mathrm{M}, \mathrm{A}$, perceptions of renqing, overall justice & $1107.595(454)$ & $2.440^{* *}$ & & .054 & .067 & .915 & .915 & .907 \\
\hline 3 & Three factors: B, M, and A combined into one factor & 1955.851(461) & $4.243^{* *}$ & $848.256^{* *}$ & .082 & .100 & .805 & .806 & .790 \\
\hline 4 & One factor: five factors combined into one factor & $3655.509(464)$ & $7.878^{* *}$ & $2547.914 * *$ & .117 & .146 & .584 & .585 & .555 \\
\hline
\end{tabular}

Notes: $* * p<.01 . \mathrm{B}=$ Benevolence, $\mathrm{M}=$ Morality, $\mathrm{A}=$ Authoritarianism. 
Table 2 Means, standard deviations, correlations, and scale reliabilities of all variables involved in the study

\begin{tabular}{|c|c|c|c|c|c|c|c|c|c|c|c|c|c|}
\hline Variables & Mean & SD & 1 & 2 & 3 & 4 & 5 & 6 & 7 & 8 & 9 & 10 & 11 \\
\hline $2 \mathrm{Age}$ & 33.77 & 8.26 & $-.171^{* *}$ & & & & & & & & & & \\
\hline 3 Tenure & 9.61 & 8.99 & $-.143 *$ & $.853 * *$ & & & & & & & & & \\
\hline 4 Education level & 3.35 & 1.03 & $.177 * *$ & $-.409 * *$ & $-.337 * *$ & & & & & & & & \\
\hline 6 Ownership & 1.60 & 1.15 & $.242 * *$ & $-.237 * *$ & $-.352 * *$ & .067 & $-.130 *$ & & & & & & \\
\hline 7 Benevolence & 4.02 & 1.29 & $-.203^{* *}$ & $.203 * *$ & $.143^{*}$ & -.055 & $.138 *$ & .013 & $(.923)$ & & & & \\
\hline 8 Morality & 4.54 & 1.29 & -.058 & .105 & .057 & -.020 & .019 & .011 & $.740 * *$ & $(.959)$ & & & \\
\hline 11 Overall Justice & 4.18 & 1.13 & -.097 & $.112 *$ & $.140 *$ & $-.116^{*}$ & .036 & .019 & $.433 * *$ & $.492 * *$ & -.082 & $.587 * *$ & $(.929)$ \\
\hline
\end{tabular}

Notes: $N=325$. Cronbach's alphas are in parentheses on the diagonal. ${ }^{*} p<.05 ; * * p<.01$; two-tailed tests. 
Table 3 Polynomial regression results for perceptions of renqing

\begin{tabular}{|c|c|c|c|c|}
\hline \multirow{2}{*}{ Variables } & \multicolumn{4}{|c|}{ Perceptions of renqing } \\
\hline & M1 & M2 & M3 & M4 \\
\hline Intercepts & $2.21 * *$ & $2.24 *$ & $2.43^{*}$ & 2.23 \\
\hline Gender & $-.181 * *$ & $-.121 *$ & -.088 & $-.148^{*}$ \\
\hline Age & -.106 & -.211 & -.247 & -.198 \\
\hline Tenure & .069 & .048 & .073 & .104 \\
\hline Education & $-.132 *$ & -.067 & -.114 & $-.143^{*}$ \\
\hline Position & .103 & .115 & .080 & .093 \\
\hline Ownership_1 & -.032 & -.053 & -.004 & -.022 \\
\hline Benevolence (B) & & .097 & $.451 * *$ & \\
\hline Morality (M) & & $.367 * *$ & & $.463 * *$ \\
\hline Authoritarianism (A) & & & -.022 & -.031 \\
\hline Benevolence squared & & -077 & .020 & \\
\hline Morality squared & & .044 & & .046 \\
\hline Authoritarianism squared & & & .078 & $.130^{*}$ \\
\hline Cross-product of $\mathrm{B} \times \mathrm{M}$ & & .165 & & \\
\hline Cross-product of $\mathrm{B} \times \mathrm{A}$ & & & 061 & \\
\hline Cross-product of $\mathrm{M} \times \mathrm{A}$ & & & & .035 \\
\hline$R^{2}$ & $.105 * *$ & $.403 * *$ & $.317 * *$ & $.361 * *$ \\
\hline$\Delta R^{2}$ & & $.298 * *$ & $.212 * *$ & $.256^{* *}$ \\
\hline
\end{tabular}


Notes: ${ }^{*} p<.05,{ }^{* *} p<.01$; two-tailed tests. Standardized coefficients are reported. $\mathrm{X}$ and $\mathrm{Y}$ respectively represent the two of benevolence, morality and authoritarianism in each model. For example, in M2, X represents Benevolence and Y represents Morality. Regressions include controls for ownership (3 dummies). For simplicity, we only reported Ownership_1. Specifically, Ownership_1 = State-owned enterprises. 
Table 4 Results of indirect effects tests

\begin{tabular}{|c|c|c|c|c|c|c|}
\hline Variable & \multicolumn{2}{|c|}{$\begin{array}{c}\text { Congruence of benevolence and } \\
\text { morality }(\mathrm{B}=\mathrm{M})\end{array}$} & \multicolumn{2}{|c|}{$\begin{array}{l}\text { Congruence of benevolence and } \\
\text { authoritarianism }(\mathrm{B}=\mathrm{A})\end{array}$} & \multicolumn{2}{|c|}{$\begin{array}{c}\text { Congruence of morality and } \\
\text { authoritarianism }(M=A)\end{array}$} \\
\hline Coefficient of the block variable (a path) & $.548 * *$ & & $.528 * *$ & & $.511 * *$ & \\
\hline $\begin{array}{l}\text { Coefficient of perceptions of renqing, } \\
\text { controlling for the block variable (b path) }\end{array}$ & & $.293 * *$ & & $.344 * *$ & & $.367 * *$ \\
\hline $\begin{array}{l}\text { Indirect effect of congruence via perceptions of } \\
\text { renqing }(\mathrm{a} \times \mathrm{b})\end{array}$ & & $.243 * *$ & & $.279 * *$ & & $.272 * *$ \\
\hline \multirow[t]{2}{*}{ 99\% bootstrapped CIs for indirect effect $(a \times b)$} & & {$[.086, .450]$} & & {$[.122, .486]$} & & {$[.124, .466]$} \\
\hline & \multicolumn{2}{|c|}{$\begin{array}{c}\text { Incongruence of benevolence and } \\
\text { morality }(\mathrm{B}=-\mathrm{M})\end{array}$} & \multicolumn{2}{|c|}{$\begin{array}{c}\text { Incongruence of benevolence and } \\
\text { authoritarianism }(B=-A)\end{array}$} & \multicolumn{2}{|c|}{$\begin{array}{c}\text { Incongruence of morality and } \\
\text { authoritarianism }(M=-A)\end{array}$} \\
\hline Coefficient of the block variable (a path) & $-.500 * *$ & & $.542 * *$ & & $.536^{* *}$ & \\
\hline $\begin{array}{l}\text { Coefficient of perceptions of renqing, } \\
\text { controlling for the block variable (b path) }\end{array}$ & & $.354 * *$ & & $.311 * *$ & & $.338 * *$ \\
\hline $\begin{array}{l}\text { Coefficient of the block variable, controlling } \\
\text { for perceptions of renqing (c' path) }\end{array}$ & & $-.231 * *$ & & $.325^{* *}$ & & $.284 * *$ \\
\hline $\begin{array}{l}\text { Indirect effect of congruence via perceptions of } \\
\text { renqing }(\mathrm{a} \times \mathrm{b})\end{array}$ & & $-.350 * *$ & & $.309^{* *}$ & & $.280 * *$ \\
\hline
\end{tabular}


Notes: CI, Confidence interval. CIs not containing zero are interpreted as significant. Results are based on 10,000 bootstrap samples

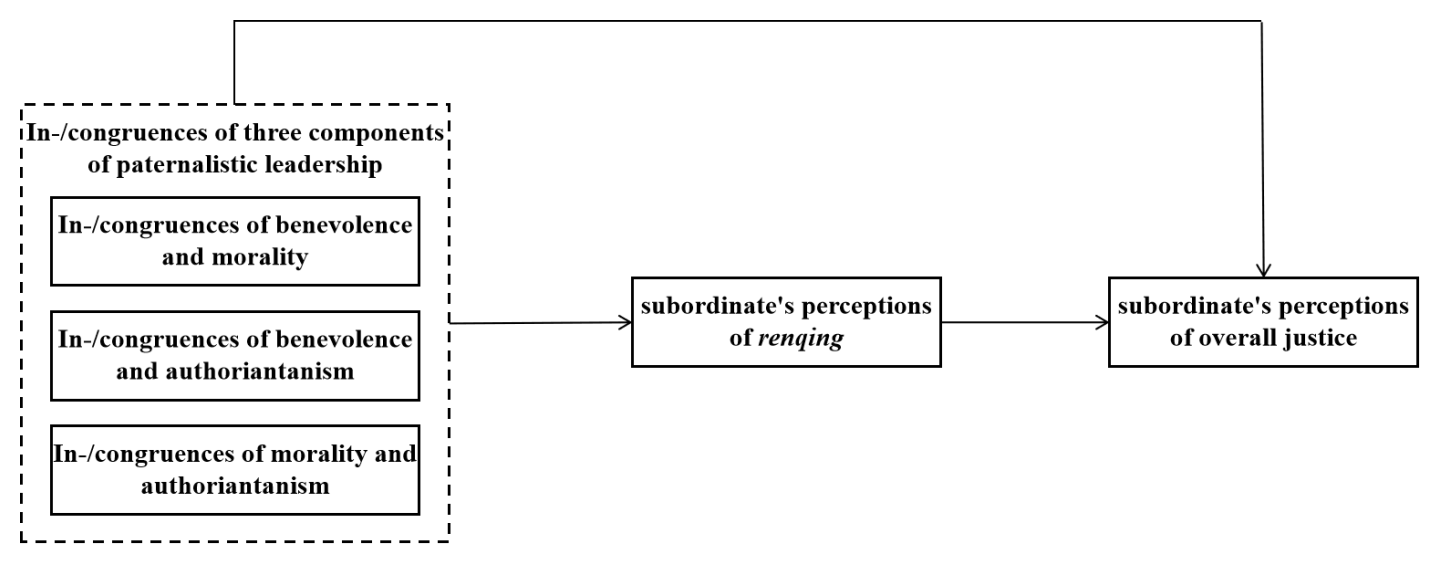

Figure 1 Theoretical framework of this study 


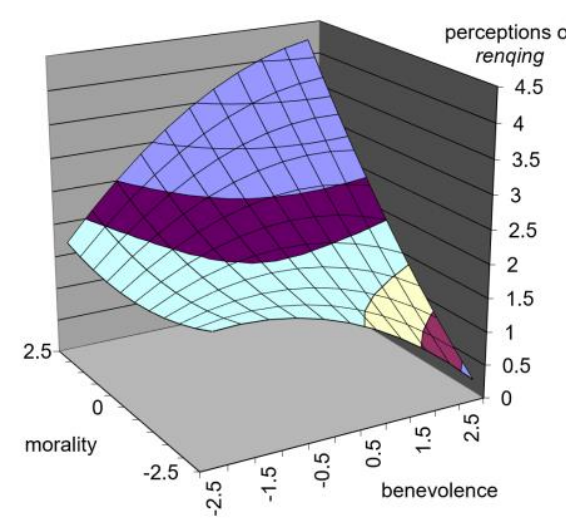

(2a)

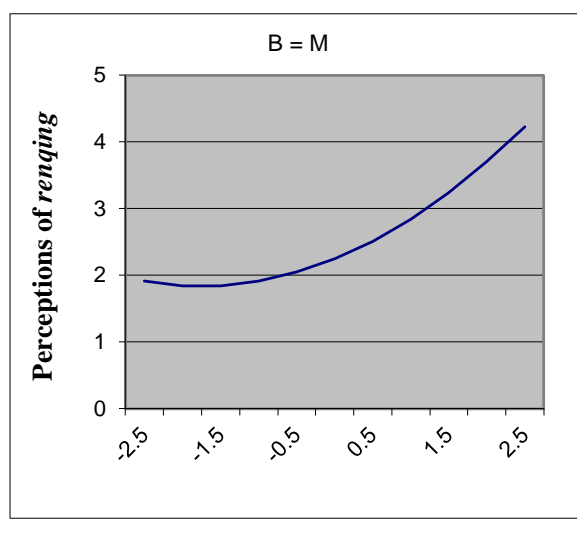

(2b)

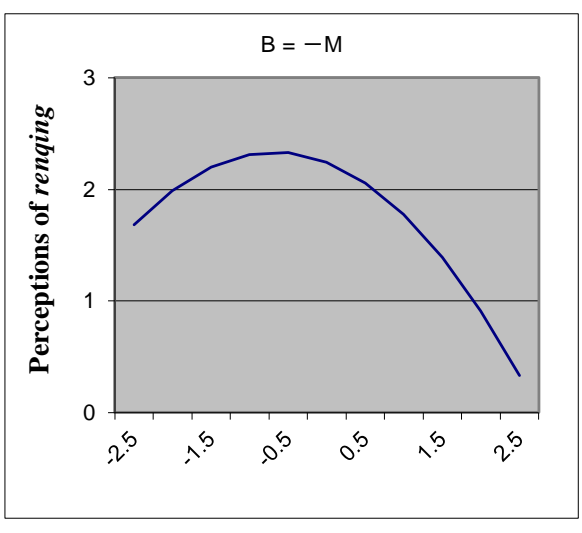

(2c)

Figure 2 The response surface of $\mathrm{B}=\mathrm{M}$ and $\mathrm{B}=-\mathrm{M}$ on subordinates perceptions of renqing

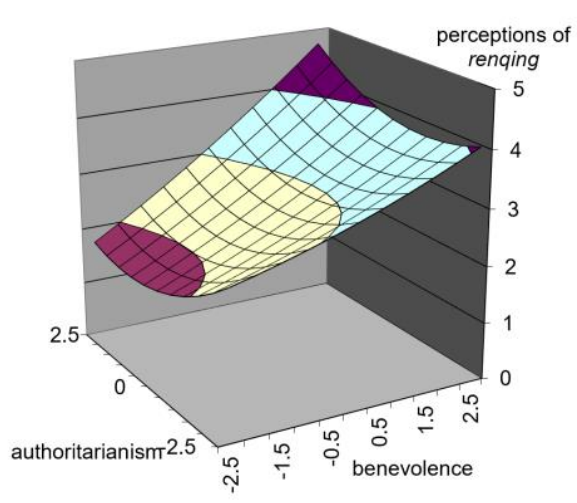

(3a)

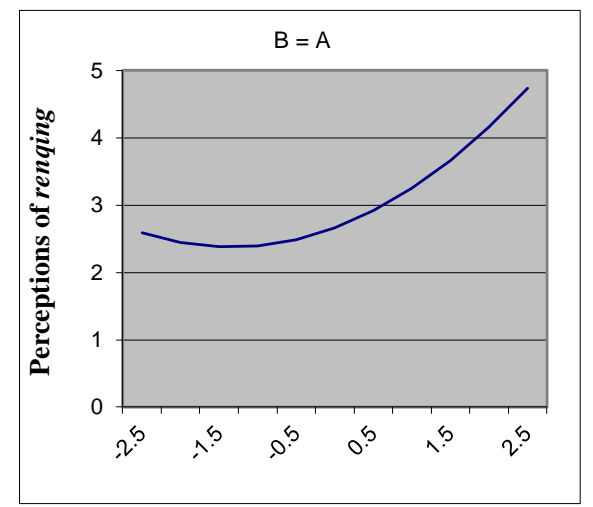

(3b)

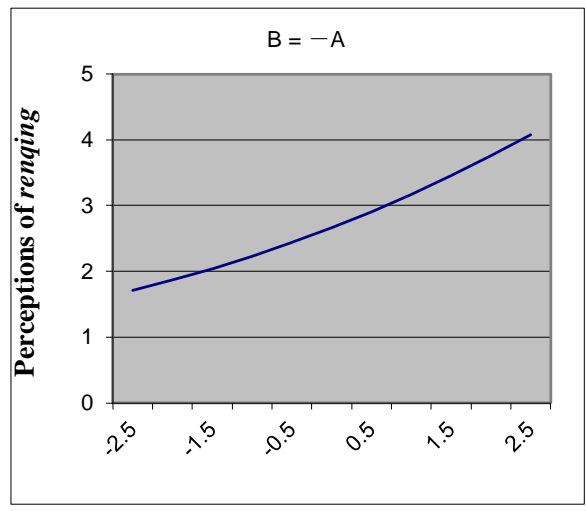

$(3 \mathrm{c})$

Figure 3 The response surface of $\mathrm{B}=\mathrm{A}$ and $\mathrm{B}=-\mathrm{A}$ on subordinates perceptions of renqing 


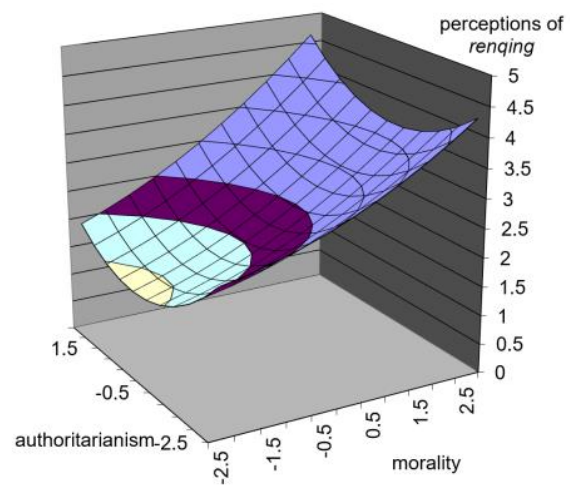

(4a)

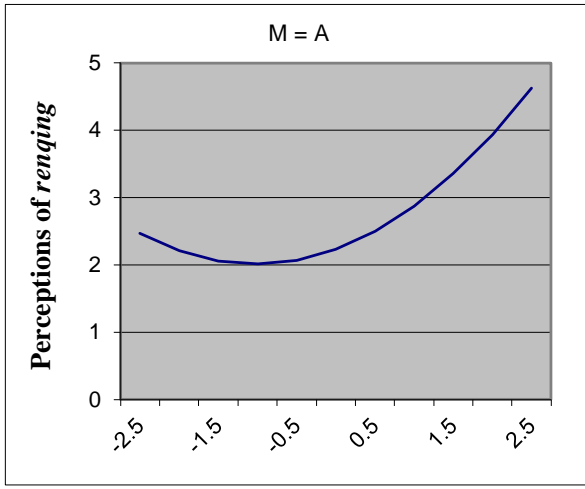

(4b)

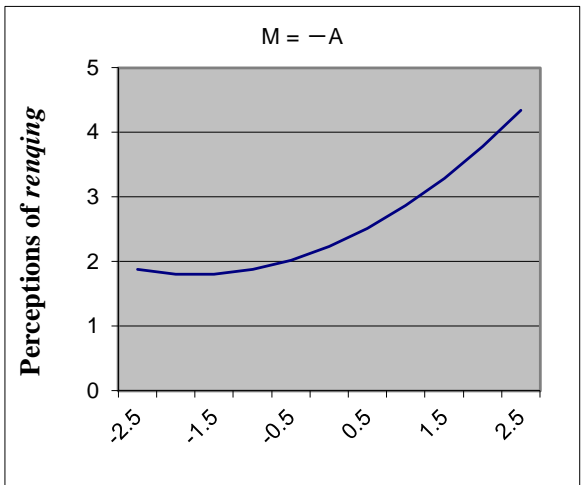

(4c)

Figure 4 The response surface of $\mathrm{B}=\mathrm{A}$ and $\mathrm{B}=-\mathrm{A}$ on subordinates perceptions of renqing 